Article

\title{
Improved Loss-of-Lubrication Performance with Lubricants Containing Nano-Graphene Platelets and Ionic Liquids
}

\author{
Nikhil Murthy ${ }^{1, *}$, Amarendra K. Rai ${ }^{2}$ and Stephen Berkebile ${ }^{1}$ \\ 1 CCDC Army Research Laboratory, 6340 Rodman Road, APG, MD 21005, USA; \\ stephen.p.berkebile.civ@mail.mil \\ 2 UES Inc., 4401 Dayton-Xenia Road, Dayton, OH 45432, USA; arai@ues.com \\ * Correspondence: nikhil.k.murthy.civ@mail.mil
}

Received: 30 September 2020; Accepted: 2 November 2020; Published: 10 November 2020

\begin{abstract}
In this study, nano-graphene platelets (NG) and a phosphonium-phosphate-based ionic liquid (IL) were studied as additives to rotorcraft gearbox oil to improve the resistance to scuffing under starved lubricated conditions. Behavior under a loss of lubrication was evaluated using a high-speed ball-on-disk tribometer and a reciprocating cylindrical pin-on-disk tribometer. In addition, the scuffing load and friction over a wide range of sliding and entrainment speeds was determined. On the high-speed ball-on-disk tribometer, an oil blend containing both NG and IL additives was able to operate two times longer than an unadditivized oil before scuffing after the lubrication supply was removed. The increase in time to scuffing was larger for two additives together than the sum of their parts. The additives showed an increase in scuffing load individually but were detrimental when mixed together with a lower scuffing load. The combination of NG and IL show promise as additives to increase the operation time of gears during loss of lubrication, however at the potential cost of decreasing the load-carrying capacity of the oil.
\end{abstract}

Keywords: staved lubrication; ionic liquids; graphene; friction

\section{Introduction}

Aircraft, especially helicopters, place high demands on their engine and transmission lubricants. The lubricant must perform satisfactorily over a wide range of operational and environmental conditions. The loss of the primary lubrication system (oil out condition) can result in a catastrophic failure of the drive system due to the degradation of tribological performance in the highly loaded gear contacts. Thus, there is a need to increase the time that a lubrication system can provide adequate lubrication under loss of transmission lubrication for sufficient length of time to safely land the aircraft.

According to the US Army Aeronautical Design Standard (ADS)-50-PRF 5-4.3.5, rotorcraft gearboxes must be capable of operating for $30 \mathrm{~min}$ from the time the lubricant warning light turns on [1]. To meet the requirement for longer term aircraft survivability under loss of transmission lubrication, one approach is to add a secondary and completely separate emergency lubrication system. In addition to the added mechanical complexity and expense, the aircraft performance will suffer from payload loss due to additional systems weight. A better and cost-effective approach would be to develop an additive technology to enhance the lubrication performance of the currently used lubricant under starved lubrication "oil-out" conditions.

Under a loss-of-lubrication situation, the gear system is eventually forced to operate under boundary lubrication condition once enough oil has drained from the gearbox. In normal fully lubricated operation, the gear system avoids metal-on-metal contact through elastohydrodynamic 
(EHD) liquid lubricating film. During startup/shutdown and under extraordinary loading, the use of extreme pressure additives forms a low shear compounds (tribo-film) on the metal surfaces when the EHD film becomes too thin and allows the solid surface asperities to touch. The tribo-film allows for smooth operation of the mechanical devices with lower friction and prevents the occurrence of scuffing. We hypothesize that if a robust (adherent and thermally stable) tribo-film developed during normal operation with lubricant can be formed, it may continue to function under a subsequent loss-of-lubrication condition allowing for the gears to operate for significantly longer period of time with much lower friction and wear.

Ionic liquids (ILs) embody a number of highly desirable attributes when used in advanced lubricant formulations. The potential of the ionic liquids as lubricants has been demonstrated for several different chemistries [2-6]. Moreover, due to its inherent polarity, an IL is expected to adsorb strongly on the metallic tribo-contact surfaces leading to robust tribo-film. Indeed, Lu et al. [2] and Jimenez et al. [4] revealed that an IL will adsorb strongly on the metallic tribo-contact surfaces leading to a robust tribo-film when compared to charge-neutral hydrocarbon and ester-based lubricants. This robust tribo-film is expected in turn to provide lower friction and increased resistance to scuffing for longer time under loss-of-lubrication situation.

One issue regarding the use of neat ILs as a drop-in replacement for the conventional hydrocarbon or synthetic based lubricants is their intrinsically high cost. It has been demonstrated that ILs can be used successfully as additives in unformulated mineral oil to lower friction and wear characteristics of a given tribo-contact pair $[7,8]$. This important finding opens the door to adding small amounts $(1-5 \mathrm{wt} \%)$ of an appropriate IL to commercially available lubricants at a price point commensurate with that of state-of-the-art additives. The beneficial tribo-film on the contact surfaces was found to be related to the IL additive due to the selective adsorption of the IL anion/cation pair onto the metallic contact pair, which provided lower friction and wear [8]. Sharma et al., having explored the use of phosphonium-based ILs as an ashless alternative to zinc dialkyldithiophosphate (ZDDP) in engine oil, observed an improvement in friction and wear [9].

The enhanced lubricity provided by ILs can be further complemented by the use of nanomaterials as lubricant additives. Nanomaterials have recently emerged as another approach to additive development for enhanced lubrication and heat transfer capability [10-14]. For example, the tribological performance of a lubricant can be further enhanced by the addition of carbon-based nanoparticles [11,13]. Many mechanisms have been suggested for the friction/wear reduction induced by nanoparticles, such as the mending effect, rolling effect, ball bearing effect, colloidal effect, protective film and third body material transfer [14]. In the mending mechanism the nanoparticles fill surface grooves and/or adhere to the wear surface. Recent studies have shown ILs and nanoparticle additives to be synergistic, possibly due to aided suspension of the particles $[15,16]$.

In recent years, nanoscale graphene (NG) platelets have shown promise and studies have shown that small quantities of $0.05 \mathrm{wt} \%$ have improved friction and wear in palm-oil ester-based lubricants $[17,18]$. Omrani et al. observed reduction in friction and wear in canola oil with optimal concentration at $0.07 \mathrm{wt} \%$ [19]. Cristea et al. looked at NG additive at $0.25-1 \mathrm{wt} \%$ in soybean oil and found reduction in normalized wear at the more severe conditions and low concentrations [20]. Zhang et al. have found an optimal concentration of NG in synthetic oil was between $0.02 \%$ and $0.06 \%$ with the lowest coefficient of friction (COF) at $0.02 \%$. [21]. Ota et al. have theorized based on their work that NG provides a protective film with high thermal conductivity, thus preventing high temperatures and surface degradation [22].

In this work, IL and nanoscale graphene (NG) platelets were added to a common rotorcraft gear lubricant conforming to DoD-PRF-85734 [23]. The tribological behavior of the DoD-PRF-85734 oil with and without the IL and NG particles was determined and compared. The potential of the additive package for enhanced tribological performance under loss of lubrication condition was demonstrated. 


\section{Materials and Experimental Procedure}

A DoD-PRF-85734 rotorcraft transmission oil, Aeroshell 555, was used both for the baseline measurements and for the additivized blends of oil. Phosphonium phosphate ionic liquid, trihexyltetradecylphosphonium bis(2-ethylhexyl)phosphate, was sourced from Covalent Associates, Woburn, MA. This IL has been previously shown to exhibit no corrosion on grey cast-iron and AISI 52,100 steel [24,25]. The molecular structure of the trihexyltetradecylphosphonium bis(2-ethylhexyl)phosphate IL (referred to in this report as IL) is detailed by Yu et al. [24].

It was determined that the IL was completely miscible with DoD-PRF-85734 under the entire test conditions described herein. For comparison purposes, a small amount of DoD-PRF-85734 lubricant was also subjected to the same conditions. No visible changes in DoD-PRF-85734 or DoD-PRF-85734 + $5 \mathrm{wt} \%$ IL lubricant blend were observed when freezing at $-13^{\circ} \mathrm{C}$. This observation indicated that the 5 -wt $\%$ IL neither froze nor phased out of solution at subzero temperatures.

Nano-graphene (NG) platelets of dimension 1 to $5 \mathrm{~nm}$ were selected. In this set of lubricant blends, IL concentration was varied from $1 \mathrm{wt} \%$ to $5 \mathrm{wt} \%$ while keeping the NG concentration fixed at $0.02 \mathrm{wt} \%$, which is 4 to 5 times less concentration than in similar studies of graphene added to oil $[26,27]$. The lubricant blends of DoD-PRF-85734 with IL and NG were prepared by mixing appropriate amounts of IL additive followed by 5 min ultrasonication, then the addition of the NG additive followed by 5 min of ultrasonication. Specifically, the following lubricant blends were prepared: DoD-PRF-85734, DoD-PRF-85734 + $1 \mathrm{wt} \%$ IL, DoD-PRF-85734 + $0.02 w t \%$ NG, DoD-PRF-85734 + $1 w t \%$ IL + $0.02 w t \%$ NG, DoD-PRF-85734 + $3 w t \%$ IL $+0.02 w t \%$ NG and DoD-PRF-85734 $+5 w t \%$ IL $+0.02 w t \%$ NG.

A high-speed ball-on-disk tribometer was used to conduct three experimental procedures: (1) starved (loss of) lubrication conditions under high entrainment and sliding conditions, (2) fully-lubricated friction and scuffing load experiments under high entrainment and sliding speeds, (3) friction mapping under fully-lubricated EHD lubrication and mixed lubrication with varying entrainment and sliding speeds. These experiments were conducted using the following lubricant blends: DoD-PRF-85734, DoD-PRF-85734 + $1 \mathrm{wt} \%$ IL, DoD-PRF-85734 + $0.02 \mathrm{wt} \%$ NG, DoD-PRF-85734 $+1 \mathrm{wt} \%$ IL $+0.02 \mathrm{wt} \%$ NG. The $1 \mathrm{wt} \%$ IL blends with NG were selected because a $1 \mathrm{wt} \%$ IL blend had demonstrated improved resistance to scuffing while remaining mostly within the DoD-PRF-85734 specification in a previous study [28]. The disk surface was circumferentially ground to a roughness of $\mathrm{Sa}=160 \pm 30 \mathrm{~nm}$ and case carburized to a hardness of 60 to $63 \mathrm{HRC}$. The ball specimens were $20.68 \mathrm{~mm}$ in diameter, tumble finished to a roughness of $\mathrm{Sa}=380 \pm 20 \mathrm{~nm}$ and case carburized to a hardness of $58 \mathrm{HRC}$. The lubricant was ultrasonicated for $10 \mathrm{~min}$ prior to the start of experiments. Lubricant was heated to $120^{\circ} \mathrm{C}$ during the experiments as it moved through a length of tubing before being delivered to the disk ahead of the inlet to the contact.

The high-speed ball-on-disk tribometer purchased from Wedeven Associates, Edgmont, PA, shown in Figure 1, independently controls the load, velocity of the ball at the point of contact $(\mathrm{Ub})$, the velocity of the disk at the point of contact (Ud), lubricant supply rate and temperature. Thermocouples were used to measure temperature of the disk and oil supply. The coefficient of friction (COF) was calculated within an error of $\pm 2 \%$ from a series of six load cells attached to the ball spindle mount. The entrainment speed (Ue) is defined as:

$$
\mathrm{Ue}=(\mathrm{Ub}+\mathrm{Ud}) / 2
$$

The sliding speed is:

$$
\mathrm{Us}=|\mathrm{Ub}-\mathrm{Ud}|
$$

The slip is:

$$
\text { Slip }=(\mathrm{Us}) / \mathrm{Ue} * 100 \%
$$




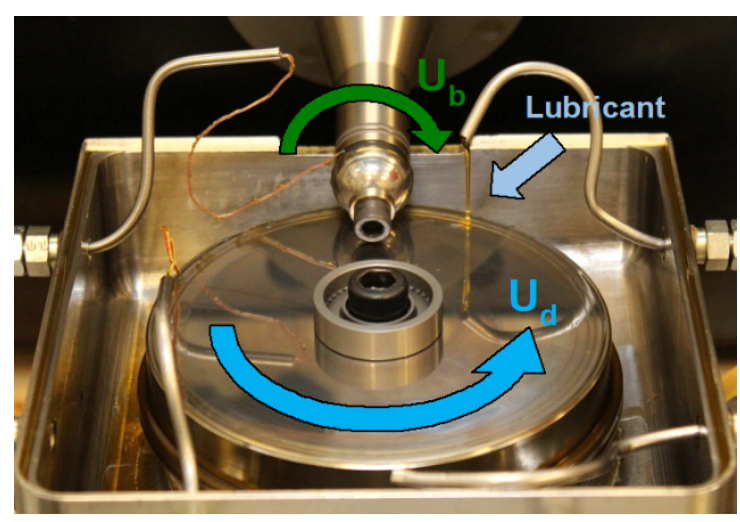

Figure 1. High speed ball-on-disk tribometer experimental setup.

During the high-speed loss-of-lubrication experiment, constant contact conditions were maintained. The sliding speed was set to $16 \mathrm{~m} / \mathrm{s}$, while a constant entrainment speed was chosen within $16 \pm 0.5 \mathrm{~m} / \mathrm{s}$ in order to minimize vibrations. The load was maintained at $100 \mathrm{~N}$ (approximately $1.3 \mathrm{GPa}$ Hertzian contact stress), and oil and disk temperatures at $125 \pm 10^{\circ} \mathrm{C}$. The lubricant was supplied to the contact for a running-in period of $10 \mathrm{~min}$. The supply was then turned off and the experiment was continued until scuffing occurred, as indicated by a spike in $\mathrm{COF}$ and an observable increase in the volume of the audible sound. A set of at least five experiments was conducted for each lubricant blend.

The scuffing load experiments were conducted at a constant entrainment and sliding speed with the load incrementally increased. The sliding speed was set to $16 \mathrm{~m} / \mathrm{s}$, while a constant entrainment speed was chosen within $16 \pm 0.5 \mathrm{~m} / \mathrm{s}$ in order to minimize vibrations. The load was maintained for $60 \mathrm{~s}$ at each of 30 load stages before increasing to the next. The load stages $(\mathrm{N})$ were as follows: 17.76, 28.86, 34.19, 41.51, 48.84, 58.61, 68.38, 78.14, 87.91, 100.12, 112.33, 124.54, 136.75, 151.4, 166.06, $180.71,195.36,212.45,229.55,246.64,263.74,285.94,312.57,343.66,379.18,419.14,463.54,512.38$, 565.66 and 621.6. The experiment was allowed to continue until scuffing occurred, as indicated by the same criteria described previously, at which point the current load was recorded as the scuffing load. Additional details on the loss of lubrication and scuffing load procedure were reported by Riggs, et al. [29]. One experiment was conducted for each blend.

The friction mapping experiments were conducted by cycling conditions throughout a wide range of entrainment speeds from 0.35 to $16 \mathrm{~m} / \mathrm{s}$ and slip from $0 \%$ to $100 \%$ at a constant load of $200 \mathrm{~N}$ (approximately 1.7 GPa Hertzian contact stress). During the experiment, the COF was measured while keeping slip constant and slowly ramping (gradually changing) the entrainment speed from an initial value of $16 \mathrm{~m} / \mathrm{s}$ down to $0.35 \mathrm{~m} / \mathrm{s}$ over a period of $90 \mathrm{~s}$ before ramping back up to $16 \mathrm{~m} / \mathrm{s}$ over another $90 \mathrm{~s}$. The slip was then stepped up to the next value of interest and the entrainment speed was ramped down and up again. The values for the slip (in \%) used in this experiment were: 0.54, $1.62,5,10,15,20,25,30,35,40,45,50,60,70,80,90$, and 100 . The final conditions witnessed by the test track were at $\mathrm{Ue}=16 \mathrm{~m} / \mathrm{s}$ and $100 \%$ slip. After completing one cycle, the process was repeated starting at $\mathrm{Ue}=16 \mathrm{~m} / \mathrm{s}$, slip $=0.54 \%$, until run-in of the specimen was complete. The run-in process was determined to be over when a difference in COF between subsequent cycles was less than 0.002 for each combination of entrainment speed and slip. The data in the final cycle was used to map the friction during the fully run-in state and was used to compare the various lubricant blends to the baseline oil (DoD-PRF-85734). Details on the procedure can be found in reference [30]. One experiment was conducted for each blend.

A loss of lubrication condition was simulated on a pin-on-disk tribometer from Cameron-Plint. Case-carburized AISI 9310 alloy steel was used for the tribometer specimens. As-received bulk AISI 9310 was machined to the required dimension and appropriately heat treated and case hardened to obtain a surface hardness of $60 \mathrm{HRC}$ and a case depth of $0.045-0.050$ ". The initial contact is a line contact between a pin ( $6 \mathrm{~mm}$ diameter, $6 \mathrm{~mm}$ long and blended crown radius) and a disc (1 inch 
diameter). The specimens were reciprocated with a stroke length of $9 \mathrm{~mm}$ with a frequency of $6 \mathrm{~Hz}$. The experiments were conducted at $100{ }^{\circ} \mathrm{C}$. The first $5 \mathrm{~min}$ of the test was run at $20 \mathrm{~N}$ load as a run-in period in a fully flooded condition with a cavity filled with $1-2 \mathrm{~mL}$ of lubricant. The lubricant was heated to $80^{\circ} \mathrm{C}$ and mixed prior to application. The load was then maintained at $250 \mathrm{~N}$ (approximately $700 \mathrm{MPa}$ Hertzian contact stress) for $60 \mathrm{~min}$. Finally, in order to simulate a loss-of-lubrication event, the lubricant was completely removed from the cavity, with a pipette, in which the disc was placed while the test was still running at $250 \mathrm{~N}$. The experiment was continued under a starved lubricated condition until scuffing was determined to occur, indicated by a rise in the COF above 0.3 , or the test duration (typically $300 \mathrm{~min}$ ) ended. One experiment was conducted for each blend.

\section{Results}

The $\mathrm{COF}$ of friction during the ball-on-disk loss of lubrication experiments had a similar pattern for all of the experiments. Figure 2 shows the COF during an experiment using the baseline DoD-PRF-85734 oil, but it is representative of all the experiments. It can be seen in the figure that the COF was affected by a number of events occurring during the experiments. The first 10 min consisted of the COF slowly approaching a constant value during the run-in period. When the lubricant was cut, at time equals zero in Figure 2, the COF slowly rises until a scuffing event, as marked by the magenta arrows. At the point of scuffing, the friction rises sharply. The time to scuffing was taken as the time difference between when the oil supply is turned off to the point of scuffing, and the mean is shown for all lubricants in Figure 3 with error calculated with 95\% confidence. The time to scuffing initiation was higher for all the blends with the additional additives than the baseline oil, which had a time to scuffing of $60.1 \mathrm{~s}$. The time to scuffing initiation was increased by 13\% for DoD-PRF-85734 $+0.02 \mathrm{wt} \%$ NG to $68.3 \mathrm{~s}$, $66 \%$ for DoD-PRF-85734 + $1 \mathrm{wt} \%$ IL to $99.84 \mathrm{~s}$, and 103\% for DoD-PRF-85734 + $1 \mathrm{wt} \%$ IL $+0.02 \mathrm{wt} \%$ NG to $122.1 \mathrm{~s}$. The increase in time to scuffing onset for the lubricant with both additives was more than the sum of the increases from the blends with a single additive.

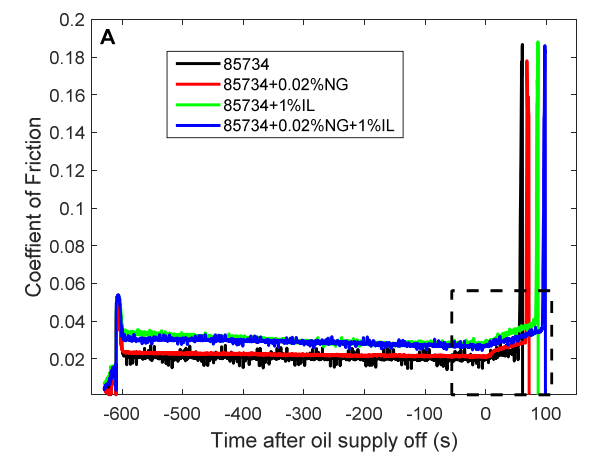

(a)

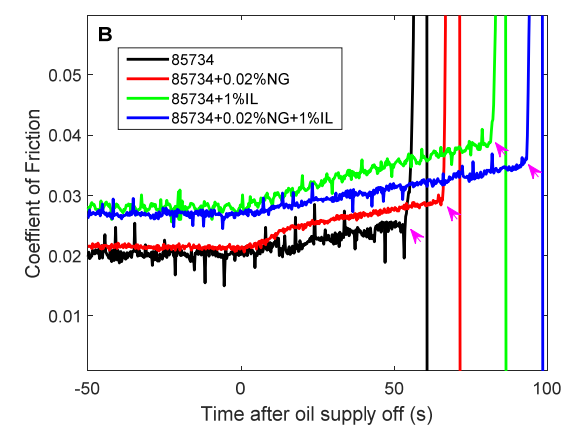

(b)

Figure 2. Coefficient of friction during ball-on-disk, loss-of-lubrication experiments. (a) Entire experiment, (b) Zoom in within the dotted. 


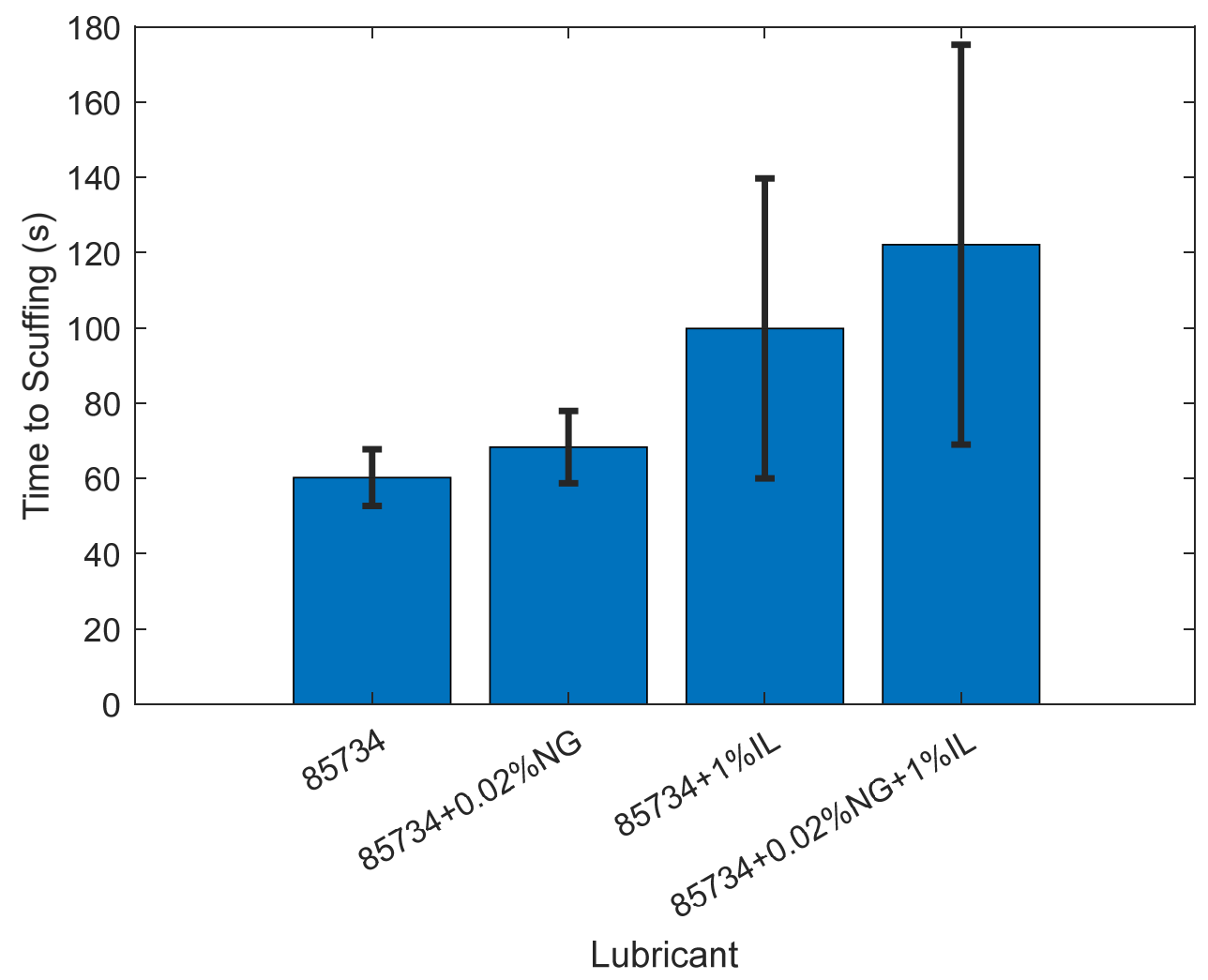

Figure 3. Average time to initiation of scuffing after shutting off oil supply in ball-on-disk, loss-of-lubrication experiments. Error with 95\% confidence interval.

In addition to observing the time to onset of scuffing of the steel specimens, the COF with the lubricant blends was extracted at key points. The COF during the ball-on-disk, loss-of-lubrication experiment was taken at the two points of interest shown in Figure 2, immediately before the lubricant supply was cut and immediately before scuffing. The mean values for the multiple runs of each lubricant blends are shown in Figure 4. The COF was similar for the baseline oil and the two blends with IL additive, around 0.026, before lubricant was cut and 0.039-0.040 immediately before scuffing. Only the DoD-PRF-85734 + $0.02 \mathrm{wt} \%$ NG blend differed in that it had a lower COF both before lubricant was cut (0.022) and before scuffing (0.034). An ANOVA analysis gives a $p$-value of 0.003 for the COF before lubricant is cut and $p$ value of 0.104 for the COF before scuffing. A low $p$-values indicates a low probability of sampling error producing a difference between the groups as large as those observed here.

The scuffing load experiments allowed for the measurement of COF as load is increased and a determination of the load at which scuffing occurs in an EHD-lubricated contact. The COF measured during the scuffing load experiments is shown in Figure 5. For all the lubricant blends, the COF decreases with time as the specimen is run in. There are small increases in COF with each step increase in load, but the overall trend appears to be downward as the specimen is progressively run in. The scuffing load for the baseline oil was $513 \mathrm{~N}$. The scuffing load for DoD-PRF-85734 $+1 \mathrm{wt} \%$ IL and DoD-PRF-85734 + $0.02 \mathrm{wt} \% \mathrm{NG}$ exceeded the maximum load of $620 \mathrm{~N}$ for this experiment. The DoD-PRF-85734 + $1 \mathrm{wt} \%$ IL $+0.02 \mathrm{wt} \%$ NG exhibited a scuffing of $165 \mathrm{~N}$, which is less than for the baseline oil. The COF for the blend with only NG additive follows closely with the COF for the baseline oil. The COF during the experiment was higher for the two blends with IL (about 0.045 at $100 \mathrm{~N}$ ) than the two blends without (about 0.03 at $100 \mathrm{~N}$ ) over the full range of loads, however a more rapid decrease in COF was seen over time for the blend with IL and NG than the blend with only IL. 


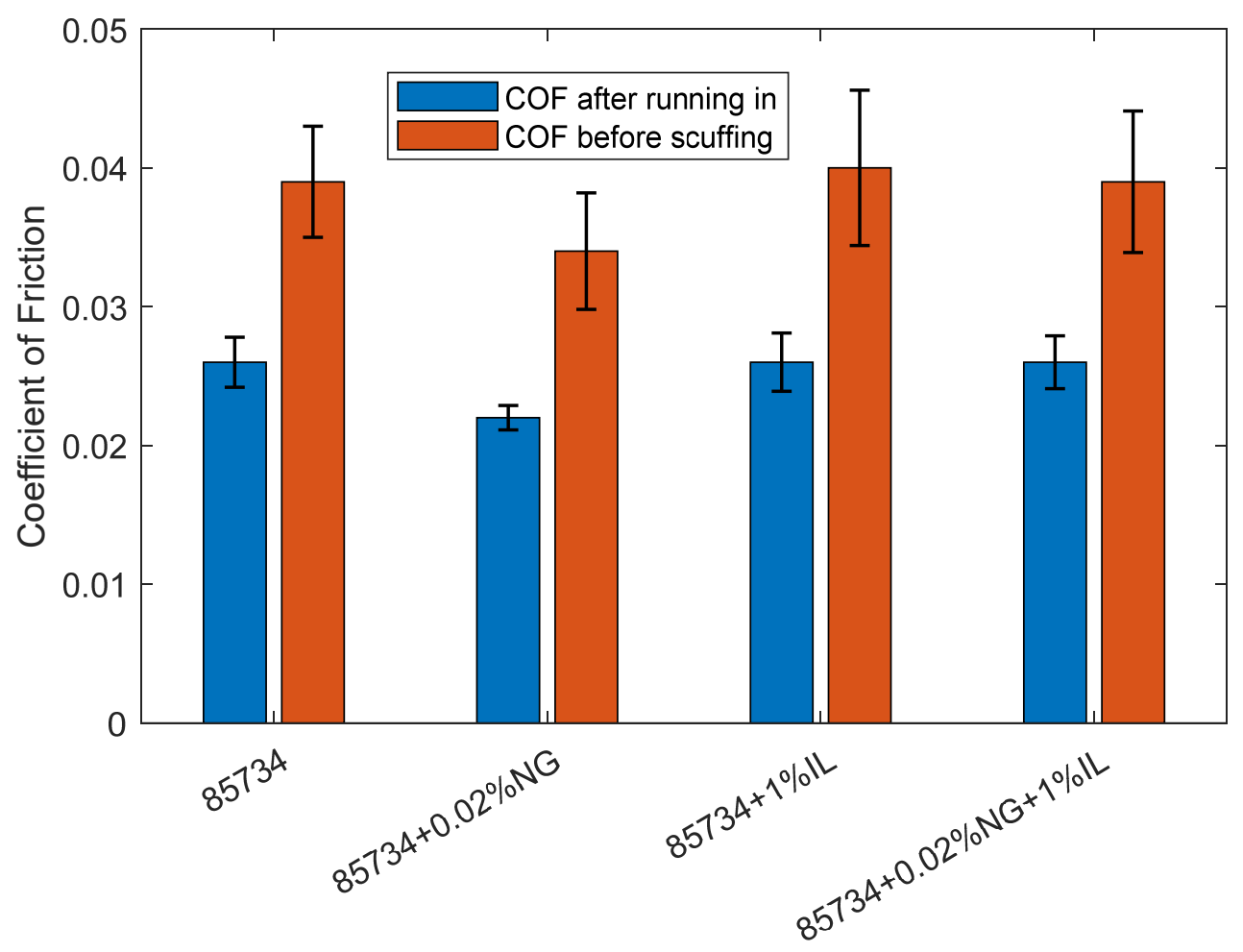

Lubricant

Figure 4. Coefficient of friction (COF) after running in and just before initiation of scuffing in high speed elastohydrodynamic contact. Error with $95 \%$ confidence interval.

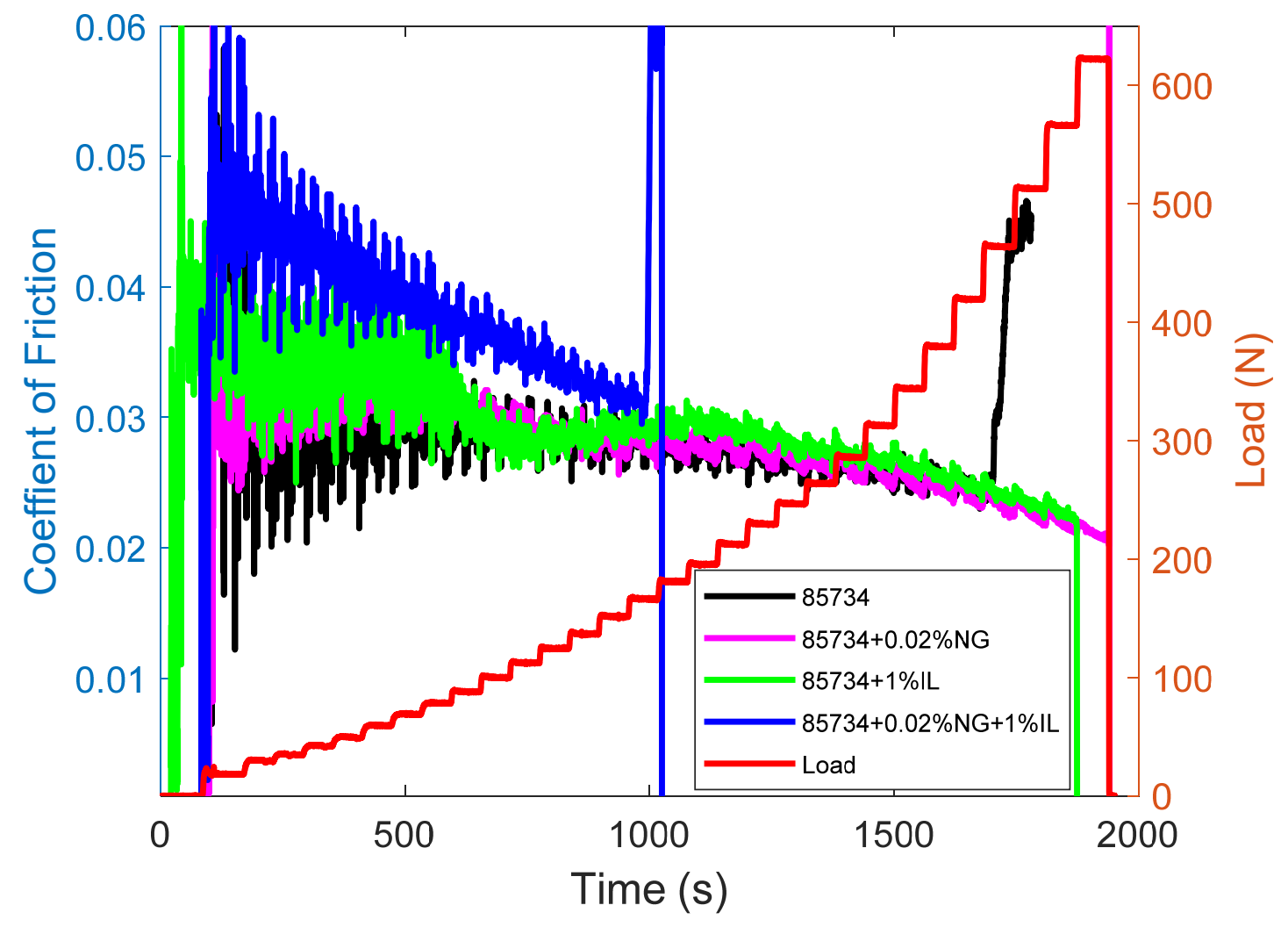

Figure 5. COF and applied load during scuffing load experiments. 
The friction mapping experiments allowed the measurement of the COF for the various lubricants with a complete run-in, fully lubricated contact at varying sliding and entrainment speeds. A comparison of the lubricant blends with additives to the baseline, unadditivized DoD-PRF-85734 oil is given in Figure 6 as the difference in COF between the lubricant blends and COF of the baseline oil for all of the sliding conditions (UE/slip \%). The DoD-PRF-85734 + $1 \mathrm{wt} \% \mathrm{IL}+0.02 \mathrm{wt} \% \mathrm{NG}$ blend is excluded from these results due to scuffing that occurred during the experiment. Negligible differences in COF were observed between the DoD-PRF- $85734+0.02 \mathrm{wt} \% \mathrm{NG}$ blend and the baseline oil across all operational speeds, as indicated by the low values in the figure. However, the DoD-PRF-85734 $+1 \mathrm{wt} \%$ IL oil showed a slight increase in COF below entrainment speeds of about $4 \mathrm{~m} / \mathrm{s}$. The difference in COF appeared to increase towards the low entrainment speeds and high slip \% conditions and is largest at $100 \%$ slip and $0.35 \mathrm{~m} / \mathrm{s}$ entrainment speed where the difference in COF is 0.004 . After complete run-in, the surface roughness within the wear track was $\mathrm{Sa}=70 \pm 10 \mathrm{~nm}$ for DoD-PRF-85734, Sa $=120 \pm 30 \mathrm{~nm}$ for DoD-PRF-85734+ $0.02 \mathrm{wt} \% \mathrm{NG}$, and Sa $=110 \pm 10 \mathrm{~nm}$ for DoD-PRF-85734+ $1 \mathrm{wt} \% \mathrm{IL}$.

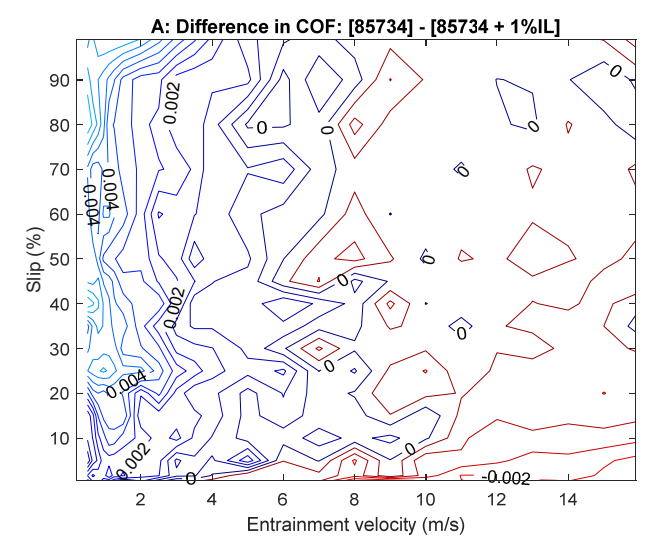

(a)

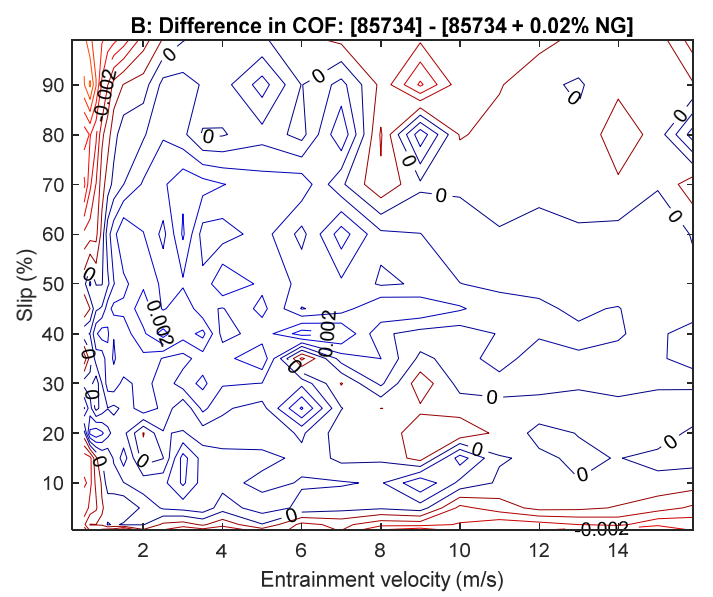

(b)

Figure 6. Difference in COF under different contact velocity conditions between the lubricant blends and baseline lubricant. (a) 85734 and $85734+1$ wt.\% IL, (b) 85734 and $85734+0.02$ wt.\% nanoscale graphene (NG).

The COF during the loss-of-lubrication experiments in a reciprocating contact is shown in Figure 7 for the various lubricant blends. During these experiments the COF quickly decreased to a stable value during the initial run-in. The COF remained mostly stable until the scuffing event, which resulted in a large increase in friction. The time to the onset of scuffing is taken from the time the oil is cut to the time the COF exceeds 0.3. The time to scuffing initiation was determined to be $12.65 \mathrm{~min}$ for DoD-PRF-85734, $25.55 \mathrm{~min}$ for DoD-PRF-85734 + $1 \mathrm{wt} \% \mathrm{IL}+0.02 \mathrm{wt} \% \mathrm{NG}$, and $143.11 \mathrm{~min}$ for DoD-PRF-85734 $+3 \mathrm{wt} \%$ 
IL $+0.02 w t \%$ NG. The COF never exceeded 0.3 with DoD-PRF-85734 $+5 w t \%$ IL $+0.02 w t \%$ NG for the 304 min of operation before the experiment was stopped.

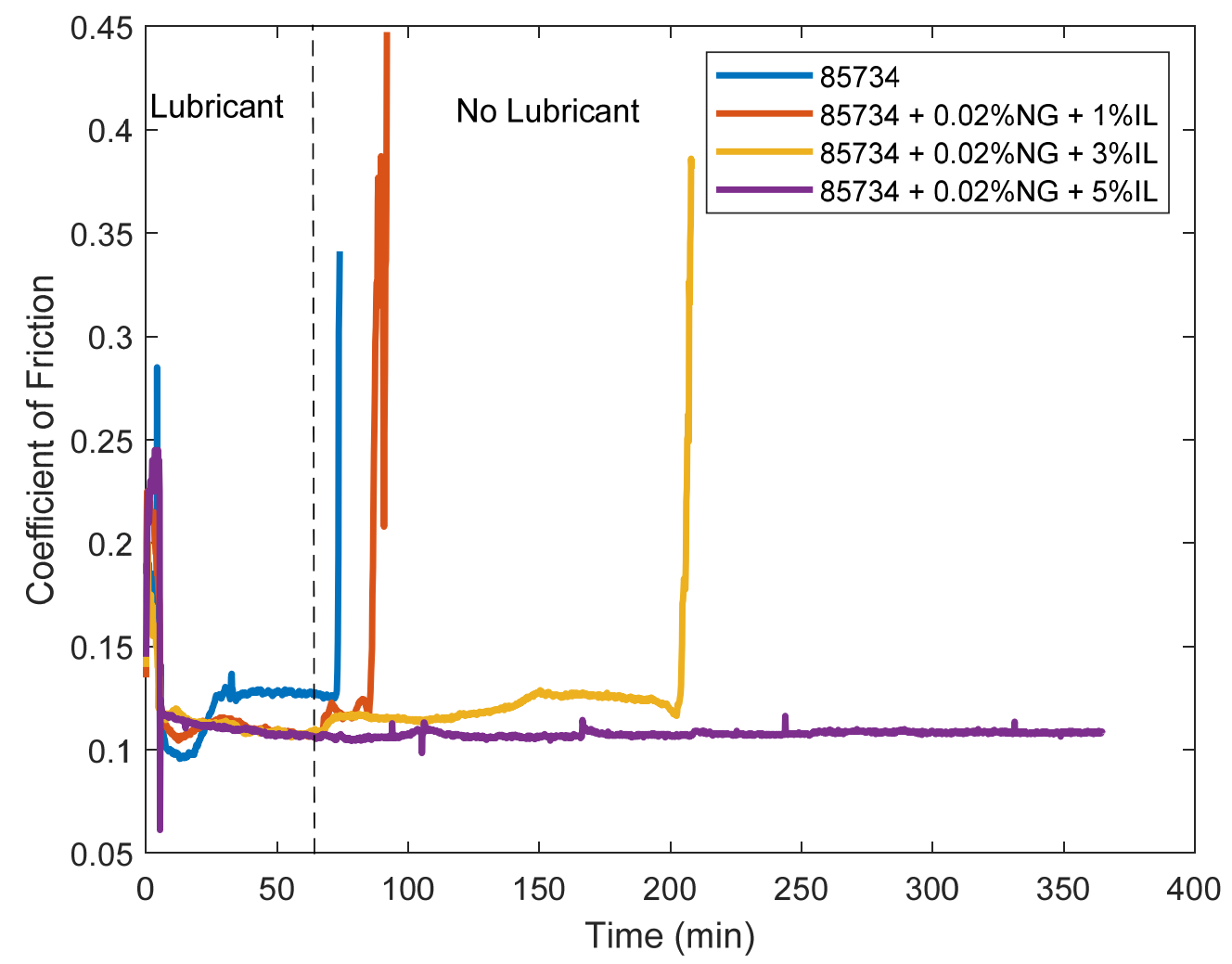

Figure 7. Coefficient of friction during reciprocating pin-on-flat, loss-of-lubrication experiments. The dotted line shows the time of lubricant removal.

\section{Discussion}

From the results we are able to get an understanding of how the IL and NG additives would affect a system in the event of a loss-of-lubrication event. The results of the ball-on-disk, loss-of-lubrication experiments show that both the IL and the NG increase the time to the initiation of scuffing. These additives have a synergistic effect, where together the increase in time to scuffing onset is greater than the sum of the increase from each component alone. The reciprocating loss-of-lubrication experiment also shows an increase in the time to scuffing initiation when including the additives over that of the base oil. In this experiment, the time to scuffing initiation increased with higher IL concentration, demonstrating that even at higher concentration of IL the two additives are able to perform together.

In contrast, when evaluating load at which scuffing occurs, the results suggest a discord between the two additives. We observed an increase in the scuffing load compared to the unadditivized oil when using either the IL or NG alone, however when the additives were together, we observed a much lower scuffing load. This lower load is likely the reason why we were unable to complete the friction mapping experiments. We were able to complete the loss-of-lubrication experiments for the oil containing both IL and NG additives because the applied load was less than the scuffing load even though the speeds were similar to the scuffing load experiments.

Starved lubrication through removal of the oil source and increasing the load both bring the surfaces of the steel into more intimate contact. Each additive alone tends to increase the resistance to scuffing for the two methods of increasing contact severity. However, the propensity to scuff behaves very differently between these two methods for the combination of IL and NG additives. The tribofilms that presumably prevent scuffing did not seems to interfere with one-another during starved lubrication 
but did not offer the same protection at increased loads during full-film lubrication. The reason for this difference may be the run-in processes that the two scuffing determination methods experience, resulting in different surface roughness and possibly different tribofilms. However, that run-in process is complex, as the following analysis of coefficient of friction reveals.

The last observation was with the COF and run-in behavior of the steel when using the different oil blends. During the ball-on-disk, loss-of-lubrication experiment, little difference was observed between the baseline oil and the two blends with IL at the key points during running in and just before initiation of scuffing. This result is in agreement with the friction mapping results where differences in COF only begin to be significant at lower entrainment speeds. However, during the scuffing load experiments, a high COF was observed for both blends containing IL for all loads. We can see from the surface roughness of friction mapping wear tracks that the surfaces run-in less with the blends containing IL as the IL seems to hinder the smoothing effect of run-in. The hindrance of run-in resulting in a rougher surface can be seen to increase the COF in the mixed lubrication regime of the IL-containing blend over that of the baseline oil at entrainment velocities below $2 \mathrm{~m} / \mathrm{s}$ in Figure 6 . Another contrast in COF was observed for the plain NG blend when compared to baseline oil. The NG blend had a similar COF to the baseline oil in both scuffing load and friction mapping experiments, however during the ball-on-disk, loss-of-lubrication experiment the COF was significantly lower. The low $p$-number of 0.003 and 0.104 indicate a low probability of this difference being due to sampling error. Further, when the NG and IL were used together during the load capacity experiment, the addition of the NG tended to lower the $\mathrm{COF}$ as the load was increased. Together the various trends indicate that the additives affect the COF and run-in in a complex manner, which likely depends on the contact history.

\section{Conclusions}

In this study, we characterized the viability of two lubricant additives, nano-graphene platelets and a phosphonium-phosphate-based ionic liquid, in rotorcraft gearbox oil for improving the scuffing resistance of gear steels under starved, loss of lubricated conditions. The experiments showed initial promise of the additives in increasing time to scuffing and even exhibited a synergistic effect when mixed together. This increase was higher for the two additives than the sum of the parts. The additives continue to be compatible at higher ionic liquid concentration when evaluating loss-of-lubrication performance. However, when evaluating the scuffing load, it was found that the additives, which individually outperformed the baseline oil, were a detriment when mixed together. In addition, the experiments suggest the additives have a complicated effect on the friction and run-in of the steels, dependent on the contact conditions.

Overall, an increase in the time before initiation of scuffing in high-speed mechanical contacts when the oil is removed will aid in extending the operation of a rotorcraft gearbox during a loss of lubrication. However, the capacity of the contact to carry a significant load is also important to the properties of an oil for rotorcraft transmissions and is one of the metrics that an oil passing the DOD-PRF-85734 standard must meet. This initial look at the additives appears promising, but further studies are needed to optimize the additive concentrations for better compatibility across a wider range of conditions, and to see if the decrease in load capacity general occurs. Further, studies of the tribofilms on the surfaces may reveal the effect that the IL is having on the run-in process, and the interplay between the IL and NG during both starved lubrication and under increased loads.

Author Contributions: Conceptualization, A.K.R.; methodology, N.M, A.K.R. and S.B; formal analysis, N.M.; investigation, N.M. and A.K.R.; resources, A.K.R. and S.B.; writing-original draft preparation, N.M; writing-review and editing, N.M, A.K.R. and S.B; project administration, S.B; funding acquisition, A.K.R. All authors have read and agreed to the published version of the manuscript.

Funding: This research was funded by U.S. Army, grant number W911QX-13-C-0174.

Acknowledgments: The authors are grateful to Victor Koch of Covalent Associates, Inc. for many fruitful discussions on ionic liquids. The authors would like to acknowledge the guidance and encouragement from Brian Dykas during the course of this work. 
Conflicts of Interest: The authors declare no conflict of interest.

\section{References}

1. ADS-50-PRF. Rotorcraft Propulsion Performance and Qualification Requirements and Guidelines; Army Aviation and Troop Command (US): St. Louis, MO, USA, 1996.

2. Lu, Q.; Wang, H.; Ye, C.; Liu, W.; Xue, Q. Room temperature ionic liquid 1-ethyl-3-hexylimidazolium-bis (trifluoromethylsulfonyl)-imide as lubricant for steel-steel contact. Tribol. Int. 2004, 37, 547-552. [CrossRef]

3. Ye, C.; Liu, W.; Chen, Y.; Ou, Z. Tribological behavior of Dy-sialon ceramics sliding against Si3N4 under lubrication of fluorine-containing oils. Wear 2002, 253, 579-584. [CrossRef]

4. Jiménez, A.E.; Bermúdez, M.D.; Iglesias, P.; Carrión, F.J.; Martínez-Nicolás, G. 1-N-alkyl-3-methylimidazolium ionic liquids as neat lubricants and lubricant additives in steel-aluminium contacts. Wear 2006, 260, 766-782. [CrossRef]

5. Greaves, T.L.; Drummond, C.J. Protic ionic liquids: Properties and applications. Chem. Rev. 2008, 108, 206-237. [CrossRef] [PubMed]

6. Somers, A.E.; Howlett, P.C.; MacFarlane, D.R.; Forsyth, M. A review of ionic liquid lubricants. Lubricants 2013, 1, 3-21. [CrossRef]

7. Qu, J.; Truhan, J.J.; Dai, S.; Luo, H.; Blau, P.J. Ionic liquids with ammonium cations as lubricants or additives. Tribol. Lett. 2006, 22, 207-214. [CrossRef]

8. Qu, J.; Blau, P.J.; Dai, S.; Luo, H.; Meyer, H.M. Ionic liquids as novel lubricants and additives for diesel engine applications. Tribol. Lett. 2009, 35, 181-189. [CrossRef]

9. Sharma, V.; Dörr, N.; Erdemir, A.; Aswath, P.B. Antiwear properties of binary ashless blend of phosphonium ionic liquids and borate esters in partially formulated oil (No Zn). Tribol. Lett. 2019, 67, 42. [CrossRef]

10. Rapoport, L.; Bilik, Y.; Feldman, Y.; Homyonfer, M.; Cohen, S.R.; Tenne, R. Hollow nanoparticles of WS 2 as potential solid-state lubricants. Nature 1997, 387, 791-793. [CrossRef]

11. Joly-Pottuz, L.; Ohmae, N.M.; Michel, J.; Ohmae, N. Nanolubricants; John Wiley \& Sons: Hoboken, NJ, USA, 2008; Volume 13.

12. Marquis, F.D.S.; Chibante, L.P.F. Improving the heat transfer of nanofluids and nanolubricants with carbon nanotubes. JOM 2005, 57, 32-43. [CrossRef]

13. Joly-Pottuz, L.; Bucholz, E.W.; Matsumoto, N.; Phillpot, S.R.; Sinnott, S.B.; Ohmae, N.; Martin, J.M. Friction properties of carbon nano-onions from experiment and computer simulations. Tribol. Lett. 2010, 37, 75. [CrossRef]

14. Lee, C.G.; Hwang, Y.J.; Choi, Y.M.; Lee, J.K.; Choi, C.; Oh, J.M. A study on the tribological characteristics of graphite nano lubricants. Int. J. Precis. Eng. Manuf. 2009, 10, 85-90. [CrossRef]

15. Khare, V.; Pham, M.Q.; Kumari, N.; Yoon, H.S.; Kim, C.S.; Park, J.I.; Ahn, S.H. Graphene-ionic liquid based hybrid nanomaterials as novel lubricant for low friction and wear. ACS Appl. Mater. Interfaces 2013, 5, 4063-4075. [CrossRef] [PubMed]

16. Nasser, K.I.; del Río, J.M.L.; López, E.R.; Fernández, J. Synergistic effects of hexagonal boron nitride nanoparticles and phosphonium ionic liquids as hybrid lubricant additives. J. Mol. Liquids 2020, 311, 113343. [CrossRef]

17. Azman, S.S.N.; Zulkifli, N.W.M.; Masjuki, H.; Gulzar, M.; Zahid, R. Study of tribological properties of lubricating oil blend added with graphene nanoplatelets. J. Mater. Res. 2016, 31, 1932. [CrossRef]

18. Rashmi, W.; Khalid, M.; Xiao, Y.; Arwin, G.Z. Tribological studies on graphene/TMP based nanolubricant. J. Eng. Sci. Technol. 2017, 12, 365-373.

19. Omrani, E.; Menezes, P.L.; Rohatgi, P.K. Effect of micro-and nano-sized carbonous solid lubricants as oil additives in nanofluid on tribological properties. Lubricants 2019, 7, 25. [CrossRef]

20. Cristea, G.C.; Georgescu, C.; Dima, D.; Deleanu, L. Influence of graphene as additive in soybean oil. MSEE 2018, 444, 022012.

21. Zhang, W.; Zhou, M.; Zhu, H.; Tian, Y.; Wang, K.; Wei, J.; Ji, F.; Li, X.; Li, Z.; Zhang, P.; et al. Tribological properties of oleic acid-modified graphene as lubricant oil additives. J. Phys. D Appl. Phys. 2011, 44, 205303. [CrossRef]

22. Ota, J.; Hait, S.K.; Sastry, M.I.S.; Ramakumar, S.S.V. Graphene dispersion in hydrocarbon medium and its application in lubricant technology. RSC Adv. 2015, 5, 53326-53332. [CrossRef]

23. Rai, A.K. Lubricant Additive. U.S. Patent Application No. 15/790,546, 23 October 2017. 
24. Yu, B.; Bansal, D.G.; Qu, J.; Sun, X.; Luo, H.; Dai, S.; Blau, P.J.; Bunting, B.G.; Mordukhovich, G.; Smolenski, D.J. Oil-miscible and non-corrosive phosphonium-based ionic liquids as candidate lubricant additives. Wear 2012, 289, 58-64. [CrossRef]

25. Qu, J.; Bansal, D.G.; Yu, B.; Howe, J.Y.; Luo, H.; Dai, S.; Li, H.; Blau, P.J.; Bunting, B.G.; Mordukhovich, G.; et al. Antiwear performance and mechanism of an oil-miscible ionic liquid as a lubricant additive. ACS Appl. Mater. Interfaces 2012, 4, 997-1002. [CrossRef] [PubMed]

26. Lin, J.; Wang, L.; Chen, G. Modification of graphene platelets and their tribological properties as a lubricant additive. Tribol. Lett. 2011, 41, 209-215. [CrossRef]

27. Senatore, A.; D'Agostino, V.; Petrone, V.; Ciambelli, P.; Sarno, M. Graphene oxide nanosheets as effective friction modifier for oil lubricant: Materials, methods, and tribological results. ISRN Tribol. 2013, 2013, 425809. [CrossRef]

28. Murthy, N.; Berkebile, S.; Rai, A.K.; Hille, E.; Ewin, J. Effects of ionic liquid additive concentration on scuffing and wear in Oil-Starved EHL contacts. Tribol. Trans. 2018, 61, 1117-1130. [CrossRef]

29. Riggs, M.R.; Berkebile, S.P.; Murthy, N.K. Ball-on-DiscTribometers Protocol Development: Loss of Lubrication Evaluation; US Army Research Laboratory: Aberdeen Proving Ground, MD, USA, 2016.

30. Berkebile, S.; Murthy, N. Friction Mapping as a Tool for Measuring the Elastohydrodynamic Contact Running-in Process; US Army Research Laboratory: Aberdeen Proving Ground, MD, USA, 2015.

Publisher's Note: MDPI stays neutral with regard to jurisdictional claims in published maps and institutional affiliations.

(C) 2020 by the authors. Licensee MDPI, Basel, Switzerland. This article is an open access article distributed under the terms and conditions of the Creative Commons Attribution (CC BY) license (http://creativecommons.org/licenses/by/4.0/). 